\title{
Redox implications of AMPK-mediated signal transduction beyond energetic clues
}

\author{
Simone Cardaci ${ }^{1, *}$, Giuseppe Filomeni ${ }^{1,2, *, \neq}$ and Maria Rosa Ciriolo ${ }^{1,2, \pm}$ \\ ${ }^{1}$ Department of Biology, University of Rome "Tor Vergata", Via della Ricerca Scientifica, 00133 Rome, Italy \\ ${ }^{2}$ IRCCS San Raffaele Pisana, Via di Val Cannuta, 00166 Rome, Italy \\ *These authors contributed equally to this work \\ †Authors for correspondence (filomini@bio.uniroma2.it; ciriolo@ bio.uniroma2.it) \\ Journal of Cell Science 125, 1-11 \\ (C) 2012. Published by The Company of Biologists Ltd \\ doi: $10.1242 / j c s .095216$
}

\section{Summary}

Since the discovery of AMP-dependent protein kinase (AMPK), its fundamental role in regulating metabolic pathways and the molecular mechanism underlying the regulation of its activity by adenine nucleotides has been widely studied. AMPK is not only an energy-responsive enzyme, but it also senses redox signals. This review aims at recapitulating the recent lines of evidence that demonstrate the responsiveness of this kinase to metabolic and nitroxidative imbalance, thus providing new insights into the intimate networks of redox-based signals upstream of AMPK. In particular, we discuss its well-recognized activation downstream of mitochondrial dysfunction, debate the recent findings that AMPK is directly targeted by pro-oxidant species, and question alternative redox pathways that allow AMPK to be included into the large class of redox-sensing proteins. The possible therapeutic implications of the role of AMPK in redox-associated pathologies, such as cancer and neurodegeneration, are also discussed in light of recent advances that suggest a role for AMPK in the tuning of redox-dependent processes, such as apoptosis and autophagy.

Key words: ROS, Apoptosis, Autophagy, Nitric oxide

\section{Introduction}

Living organisms derive energy from the breakdown of the molecular bonds of nutrients, and then convert it into the more usable forms of ATP and NADPH (see Box 1). Cell homeostasis depends on the maintenance of ATP levels, whose hydrolysis can be coupled to synthesis reactions, transport across membranes and other endoergonic processes. For this reason, cells actively synthesize ATP and have evolved molecular mechanisms aimed at counteracting even slight decreases of ATP (Hardie, 2011). The mutual regulation of the ATP-regenerating and ATP-consuming processes, however, does not depend on the concentration of this single metabolite, but is in response to the energy balance of the cell (Atkinson, 1970). Indeed, the concentration of ATP, which has been estimated to range from 1 to $10 \mathrm{mM}$, can be subjected to marked variations. Therefore, the absolute intracellular ATP concentration tightly depends on the concentration of the other adenylates (adenylate pool) and should be considered as a function of the adenylate energy charge, which, in accordance to the definition provided by Atkinson in 1968, is expressed as ([ATP] + $0.5[\mathrm{ADP}]) /([\mathrm{ATP}]+[\mathrm{ADP}]+[\mathrm{AMP}])$ and ranges from 0 to 1 (Atkinson, 1968).

The reversible adenylate-kinase-catalyzed reaction $(2[\mathrm{ADP}] \leftrightarrow$ $[\mathrm{ATP}]+[\mathrm{AMP}])$ is sufficiently fast in cells to maintain the reactants at their equilibrium concentrations. Under resting conditions, in which the adenylate energy charge is close to $1-$ implying that the adenylate pool size is approximately equal to the ATP concentration (Hardie et al., 2011) - adenylate kinase catalyzes the reaction in favor of ADP synthesis, thereby maintaining very low AMP concentrations (approximately one or two orders of magnitude lower than those of ADP or ATP, respectively). Under conditions that raise ATP utilization, or upon metabolic stress that interferes with ATP synthesis, adenylate kinase shifts the above reaction towards the regeneration of ATP to increase its concentration and availability. This represents a valuable tool to rapidly restore ATP concentrations with a significant increase in AMP levels. Physiologically, the relative changes in AMP concentrations are much greater than those occurring to ATP (Ataullakhanov and Vitvitsky, 2002), thereby making the ratio between AMP and ATP the most reliable indicator of the cellular energetic state (Fogarty and Hardie, 2010; Kahn et al., 2005).

AMP-dependent protein kinase (AMPK) senses even small changes in AMP concentrations, and represents the principal metabolic gatekeeper of the cell (Hardie, 2011). Upon energetic imbalance, intracellular concentrations of AMP increase, thus promoting AMPK activation (Fig. 1). Activated AMPK stimulates catabolic pathways (e.g. glycolysis and fatty acid oxidation) and, concomitantly, inhibits the rate of anabolic reactions (protein, cholesterol, triglyceride and fatty acid synthesis) to restore the correct adenylate energy charge (Hardie, 2011).

Although the binding of AMP remains the principal event triggering the activation of AMPK, recent findings have demonstrated that ADP also has a role in this process (Oakhill et al., 2011; Xiao et al., 2011), because it contributes to inhibit phosphatase-mediated dephosphorylation of AMPK (see below), for instance by protein phosphatase $2 \mathrm{C} \alpha(\mathrm{PP} 2 \mathrm{C} \alpha)$ (Fig. 1). On the basis of these results, Oakhill and co-workers suggested that AMPK is a direct adenylate-charge-sensing protein kinase instead of a specifically AMP-activated kinase (Oakhill et al., 2011). 


\section{Box 1. Interconnections between intracellular metabolic flux and redox pathways}

Cells require a constant supply of energy to sustain fundamental biological processes. In heterotrophic organisms this energy derives from the oxidation of nutrients, whose chemical bond breakdown allows electrons to be stored in more useful sinks: NADH and NADPH. NADH is mainly generated in the tricarboxylic acid (TCA) cycle and provides the electrons needed for the mitochondrial generation of ATP through oxidative phosphorylation (OXPHOS) (see figure, bottom left). By contrast, the reduction of NADP ${ }^{+}$to NADPH mainly occurs in the oxidative branch of the pentose phosphate pathway, which takes place in the cytosol (see figure, top middle). ATP and NADPH provide the energy and the reducing equivalents, respectively, to drive the majority of endoergonic processes. However, besides sustaining biosynthetic reactions, ATP and NADPH also meet the needs of all aerobic organisms to maintain their intracellular redox state. This control is warranted for keeping the balance between the generation of reactive oxygen species (ROS) - mainly produced by mitochondria - and reactive nitrogen species (RNS), and their elimination through the synergistic action of the antioxidant enzymes and the thiol-containing antioxidants, such as glutathione (GSH) and thioredoxin (Trx). Indeed, the GSH and Trx redox systems require ATP as an indispensable factor for their neo-synthesis and NADPH as a source of reductants for their regeneration (see figure, center). Disruption of redox homeostasis results in the onset of conditions known as 'nitroxidative stress', which is characterized by the accumulation of nitroxidative damage to cellular biomolecules. G6PDH, glucose-6-phosphate dehydrogenase; GCL, glutamate cysteine ligase; GR, glutathione reductase; GS, glutathione synthetase; GSH, reduced glutathione; GSSG, glutathione disulfide; HK, hexokinase; $\mathrm{NO}$, nitric oxide; $\mathrm{NO}_{2 / 3}^{-}$, nitrites and nitrates; NOS, nitric oxide synthase; PHI, phosphohexose isomerase; RNS, reactive nitrogen species; ROS, reactive oxygen species; $\operatorname{Tr} x(\mathrm{SH})_{2}$, reduced thioredoxin; $\operatorname{Trx}(\mathrm{S}-\mathrm{S})$, oxidized thioredoxin; $\operatorname{TrxR}$, thioredoxin reductase.

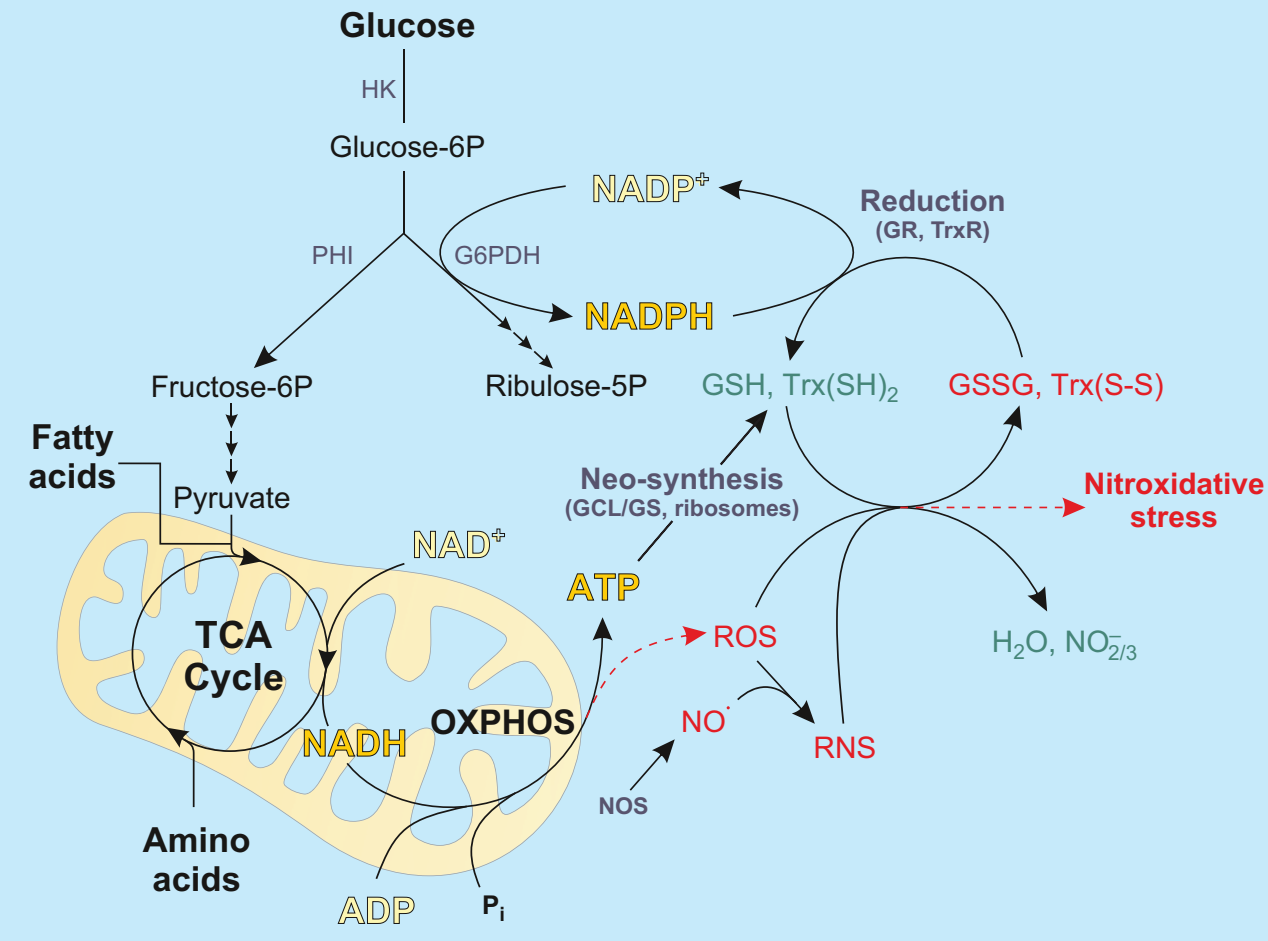

In addition to the complex regulation of AMPK by the adenylate pool, recently, AMPK has been reported to sense and respond to pro-oxidant conditions that are induced by reactive oxygen or nitrogen species (ROS and RNS, respectively), thereby activating a number of cellular processes related to the modulation of cell viability, such as apoptosis and autophagy (Poels et al., 2009). This additional feature makes AMPK a versatile molecular effector in transducing both metabolic and oxidative stimuli into phosphorylation signals that widely regulates cell response.

In this Commentary, we give a general overview of the metabolic regulation of AMPK and provide evidence supporting a possible redox-based modulation of its activity. We also highlight how the intracellular redox imbalance could regulate AMPK activity, independent of the adenylate energy charge status and attempt to evaluate the implications of this alternative activation pathway for the induction of processes governing cell viability and death. We then discuss the impact that apoptosis and autophagy, induced by redox and metabolic stimuli, can have on pathological states (neurodegeneration and cancer), in which AMPK is thought to have a role, and discuss how AMPKdependent pathophysiological processes can be driven by both metabolic and redox signaling networks.

\section{Molecular aspects and metabolic role of AMPK}

Metabolic control in higher organisms is subjected to both shortand long-term variations in nutrients. Nucleotide-based molecules (e.g. NAD, NADP, ATP) control the activity of many enzymes through feedback loops, resulting in rapid changes along metabolic fluxes. Although several energy-regulated proteins contain binding 


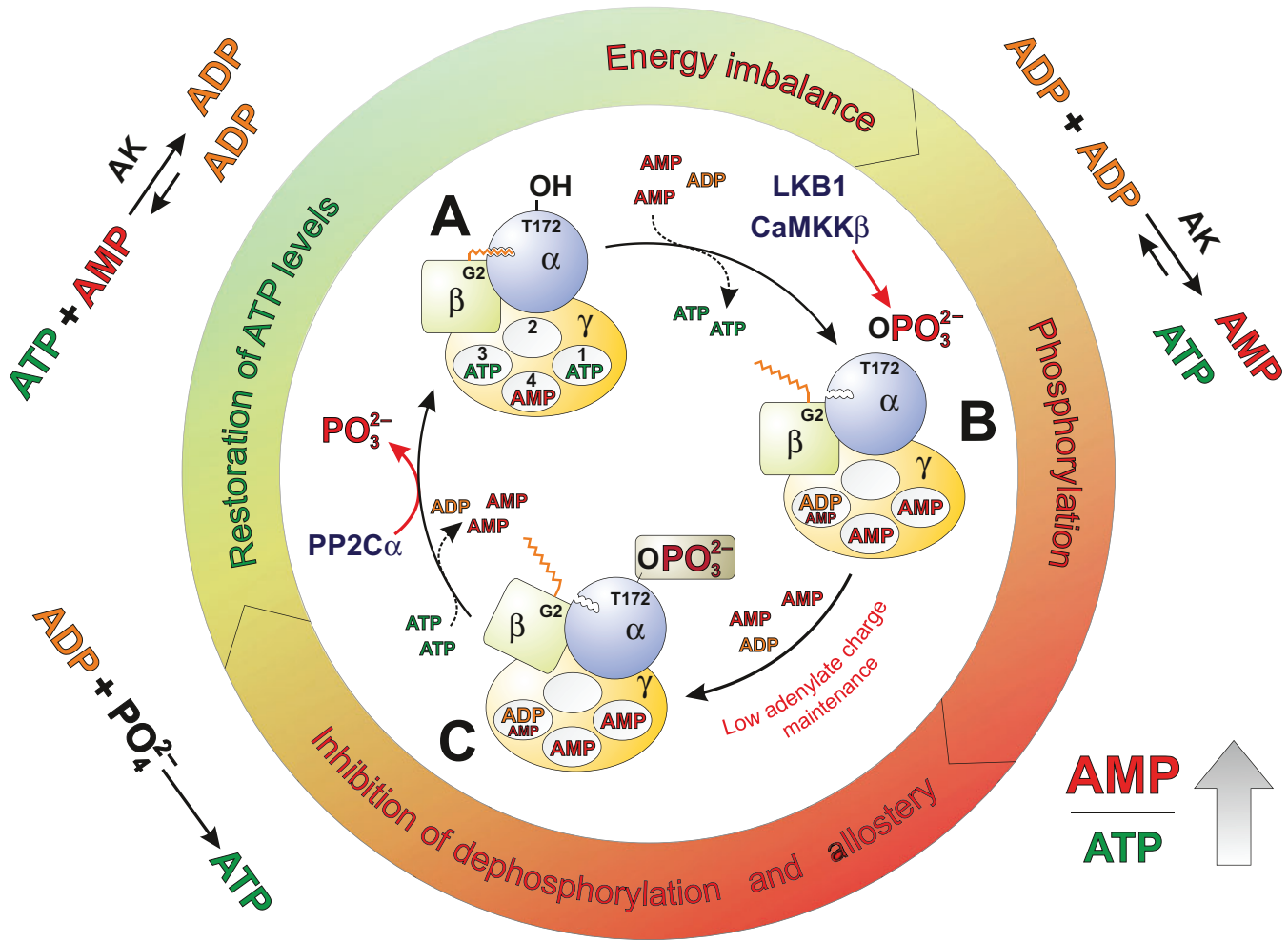

Fig. 1. Model of structure and regulation of AMPK. AMPK is a heterotrimer comprising an $\alpha$-subunit that contains the catalytic residue (T172), $\beta$ - and $\gamma$ subunits that have a regulatory role. The $\beta$-subunit is myristoylated at G2 residue (orange aliphatic chain), whereas the $\gamma$-subunit contains four nucleotide binding sites, two of which bind AMP, ADP or ATP reversibly (site 1 and site 3), one containing a non-exchangeable AMP moiety (site 4), and the last one remaining unoccupied (site 2). In conditions of high adenylate energy charge (green area of the circle), adenylate kinase (AK) catalyzes the reaction $2 \mathrm{ADP} \leftrightarrow \mathrm{ATP}+\mathrm{AMP}$ in favor of ADP synthesis (top left). AMPK is bound to ATP and inactive (A) owing to the binding of the myristoyl group to a putative myristoyl binding site within the $\alpha$-subunit, which renders it inaccessible to being modified. Upon energetic imbalance, AK shifts this reaction generating ATP and AMP (top right).

However, the relative changes in AMP are much greater than those occurring to ATP, because it has been estimated that a $10 \%$ variation of ATP levels results in a more than eightfold change in AMP concentrations. In these conditions, adenylate energy charge decreases (yellow area of the circle), AMP replaces ATP in the $\gamma-$ subunit (the precise site and mechanism responsible for this are not known) and triggers a myristoyl switch, allowing T172 to be phosphorylated (addition of phosphate group, $\mathrm{PO}_{3}{ }^{2-}$ ) by liver kinase $\mathrm{B} 1$ (LKB1) or $\mathrm{Ca}^{2+}$-calmodulin-dependent kinase kinase $\beta$ (CaMKK $\left.\beta\right)(\mathbf{B})$. Maintenance of low adenylate charge conditions (red area of the circle) establishes a high ratio between AMP and ATP (bottom right) and further allows activation of AMPK by inducing allosteric effect (up to threefold increase in AMPK activity with respect to the phosphorylated form of the protein), and preventing T172 from being dephosphorylated (gray box around $\left.\mathrm{PO}_{3}{ }^{2-}\right)(\mathbf{C})$. Recent observations indicate that ADP binds to site 1 with the same efficiency as AMP, and that this step is fundamental to prevent phosphatase-mediated dephosphorylation of T172. It has been shown that the half maximal activation of AMPK occurs at an adenylate charge of 0.91 [corresponding to $1678 \mu \mathrm{M}$ ATP, $284 \mu \mathrm{M}$ ADP and $38 \mu \mathrm{M}$ AMP] (see Oakhill et al., 2011), therefore it is reasonable to hypothesize that the contribution of ADP to retain the activated phosphorylation state of AMPK, at least physiologically, is greater than that of AMP, owing to its higher concentration. Conversely, no competition between AMP and ADP has been observed for site 3, whose binding to AMP alone underlies its allosteric effect. Induction of ATP synthesis downstream of AMPK-mediated signaling (bottom left) restores ATP levels, increases adenylate charge (green area of the circle) and allows AMP and ADP to be replaced with ATP. AMPK is then dephosphorylated by protein phosphatase $2 \mathrm{C} \alpha(\mathrm{PP} 2 \mathrm{C} \alpha)$ and inactivated.

sites for adenine ribonucleotides, almost all eukaryotes rely upon AMPK to sense and respond to changes in the adenylate energy charge (Ghillebert et al. 2011).

\section{AMPK structure and regulation}

AMPK is a heterotrimer serine threonine kinase that is composed of a catalytic $\alpha$-subunit, and regulatory $\beta$ - and $\gamma$-subunits (Hardie, 2007). The $\alpha$ subunit contains the $\mathrm{N}$-terminal serine threonine kinase domain that also includes the Thr172 residue, whose phosphorylation by upstream kinases is required for AMPK activation (Fig. 1), an autoinhibitory domain that is needed to reduce kinase activity in the absence of AMP (Crute et al., 1998; Chen, L. et al., 2009), and a C-terminal globular domain, which binds the $\beta$ - and $\gamma$-subunits.
The $\beta$-subunit contains a central carbohydrate-binding molecule (CBM), which allows AMPK to bind glycogen. Although this does not appear to affect AMPK activity (Polekhina et al., 2003), recent results indicate that diverse glycogen mimics act as inhibitors of AMPK, thereby suggesting a further role of AMPK as a glycogen sensor (McBride et al., 2009). The $\beta$-subunit has been also indicated to be cotranslationally myristoylated at Gly2 residues (Mitchelhill et al., 1997 ) and it is essential for phosphorylation of the $\alpha$-subunit at Thr172 (Fig. 1) (Oakhill et al., 2011).

The $\gamma$-subunit contains four tandem sequence repeats termed the CBS motif (from cystathionine $\beta$-synthase, where they were originally found), which function in pairs to provide four potential nucleotide binding sites. Two of these bind either 
AMP or ATP reversibly (site 1 and site 3 ), one contains a nonexchangeable, tightly bound AMP moiety (site 4), and the last one (site 2) remains unoccupied (Xiao et al., 2007; Scott et al., 2004). Recent observations indicate that ADP shows the same binding constant of AMP for site 3, which is the site that, when occupied, confers protection against dephosphorylation. As the concentration of free ADP is between 10- to 400-fold higher than that of AMP and their binding constants are similar, ADP will be more successful in competing for site 3 with ATP than AMP. Conversely, no competition between AMP and ADP has been observed for site 1, whose binding to AMP alone underlies its further role of allosteric activator of AMPK (up to threefold increase in AMPK activity with respect to the phosphorylated form of the protein).

Biochemical and genetic analyses have revealed that the liver kinase B1 (LKB1) is the major AMPK-phosphorylating kinase under condition of energy stress across metazoans (Hardie, 2007). However, the observation that cells lacking functional LKB1, such as HeLa cells, are still able to phosphorylate and activate AMPK led to the identification of $\mathrm{Ca}^{2+}$-calmodulin-dependent kinase kinase $\beta(\mathrm{CaMKK} \beta)$ and transforming growth factor- $\beta$ activated kinase 1 (TAK1) as further protein kinases involved in its activation (Hawley et al., 2005; Herrero-Martín et al., 2009).

\section{Metabolic targets}

The concerted regulation of energy homeostasis by AMPK is accomplished by phosphorylation events that inhibit the activity of proteins involved in anabolic pathways and concomitantly activate those implicated in catabolic routes; these include biosynthetic enzymes, transporters and ion channels (Hardie, 2007). The first routes discovered, where AMPK acts as metabolic gatekeeper under energy-limiting conditions, were the reduction of fatty acid and cholesterol synthesis by phosphorylation-mediated inactivation of acetyl-CoA carboxylase 2 (ACC2) and 3hydroxy-3-methylglutaryl-coenzyme A reductase, respectively (Winder and Hardie, 1996), and the stimulation of glucose uptake and oxidation by inducing the plasma membrane translocation of glucose transporter 4 (GLUT4) (Kurth-Kraczek et al., 1999). Later, it became clear that metabolic control is achieved by multiple mechanisms and occurs through both shortand long-term effects. For instance, AMPK-mediated activation of glucose uptake can occur either quickly, through the translocation of GLUT proteins to the plasma membrane (Kurth-Kraczek et al., 1999) and by direct activation of GLUT proteins located at the cell membrane (Barnes et al., 2002), or, as a long-term response through the enhanced transcription of genes encoding GLUTs, probably through the engagement of the myocyte enhancer factor2 (Zheng et al., 2001). Similarly, the inhibitory phosphorylation of ACC2 accounts for the short-term regulation of fatty acid catabolism (Merrill et al., 1997). The long-term effect of AMPK on fatty acid oxidation is exerted by an increase of mitochondrial oxidative capacity that is achieved by increasing mitochondrial biogenesis (Zong et al., 2002; Jager et al., 2007). It is worthwhile mentioning that the stimulation of fatty acid catabolism is also induced by inhibition of the lipogenic isoform 1 of ACC (ACC1), and by downregulation of lipogenic transcription factors, such as sterol regulatory element-binding protein-1 (SREBP1) and carbohydrate response element-binding protein, (ChREBP), which induce the expression of lipogenic and glycolytic genes, including those encoding ACC1, fatty acid synthase and pyruvate kinase (Zhou et al., 2001; Kawaguchi et al., 2002).
Overall, activation of AMPK on glucose and lipid metabolism results in a reduction of the plasma levels of glucose, fatty acids and triglycerides (Steinberg and Kemp, 2009). The observation that an AMPK-mediated decrease of plasma glucose occurs independently of insulin has rendered AMPK an attractive target for anti-diabetic drugs, because it allows the bypass of defects in insulin-stimulated glucose uptake in insulin-resistant individuals (Long and Zierath, 2006; Yu et al., 2010). Similarly, because insulin insensitivity and hyperlipidaemia are two components of the metabolic syndrome, AMPK-activating drugs could be beneficial for patients that are affected by obesity (Winder et al., 1999), for which only one anti-obesity medication, orlistat, is currently approved by the US Food and Drug Administration for long-term use.

\section{Activation of AMPK by nitroxidative stress}

Besides the canonical role of AMPK as a metabolic regulator, it has been recently proposed that pro-oxidant conditions as a consequence of reduced nutrient availability or hypoxia, or the selective inhibition of the mitochondrial electron transport chain, also play a pivotal role in the stimulation of AMPK activity (Hardie, 2007), as discussed below.

\section{Regulation of AMPK by ROS}

Reactive sulfhydryls are cysteine residues that, owing to the particular chemical environment, can exist in their deprotonated form at physiological $\mathrm{pH}$. In their thiolate form, cysteines can easily react with partially reduced species, such as $\mathrm{H}_{2} \mathrm{O}_{2}$ or nitric oxide (NO), to form $S$-hydroxylated or $S$-nitrosylated derivatives, respectively, which can next generate more stable, but still reversible, disulfide adducts (Fig. 2). These modifications can alter structure and function of specific proteins that are commonly named redox-sensing proteins. A decade ago, Choi and co-workers proposed that AMPK activation coupled with increased levels of $\mathrm{H}_{2} \mathrm{O}_{2}$; however, they did not refer to any possible cysteine oxidation, but suggested that the ability of $\mathrm{H}_{2} \mathrm{O}_{2}$ to activate AMPK was indirect, and occurred as a consequence of decreased intracellular levels of ATP (Choi et al., 2001). In agreement, a recent study has demonstrated that overexpression of the R531G mutant of the AMPK $\gamma 2$-subunit, which is no longer able respond to AMP or ATP, completely abolishes AMPK-mediated phosphorylative signaling when the cells were subjected to oxidative stress, indicating that AMPK activation is completely independent of redox modifications and depends only on an intracellular rise in AMP levels (Hawley et al., 2010).

Although the energy imbalance that derives from pro-oxidant conditions is probably the main means by which increased ROS generation induces the activation of AMPK in vivo, it has been demonstrated that under moderate hypoxic conditions, AMPK activation is elicited in a ROS-dependent manner, but without appreciable changes in the adenylate pool (Emerling et al., 2009). This was confirmed by pre-treating cells with antioxidants, which dampens AMPK activity without altering the ratio between ATP and AMP. Although these results give strength to the hypothesis of a direct redox regulation of AMPK, it is worthwhile noting that overexpression of the R531G mutant of the AMPK $\gamma 2$-subunit to validate the study has not been done. Moreover, no evidence that LKB1 and PP2C $\alpha$ remain unaffected by the antioxidant treatment has been provided; and the low adenylate energy charge argues the possibility that AMPK activity could be not directly modulated by intracellular redox state. Zmijewski and 


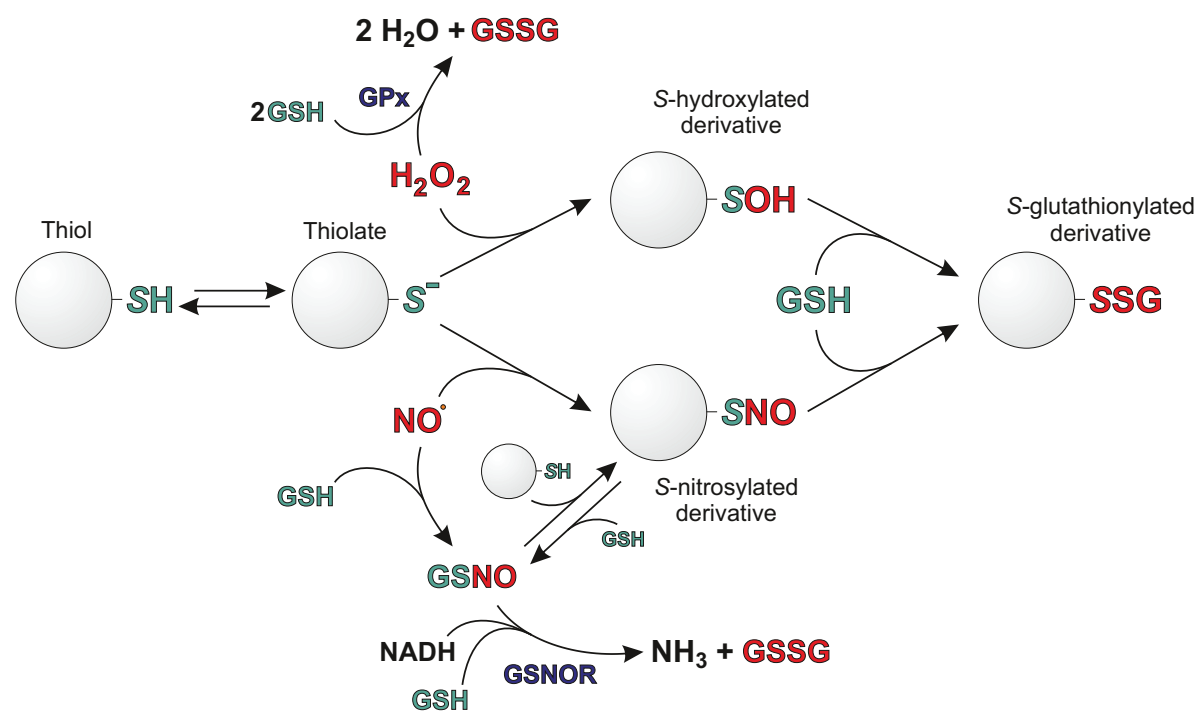

Fig. 2. Reversible nitroxidative modifications of protein thiols. Reactive thiols are cysteine residues, which because of the particular chemical environment, can exist in their deprotonated form at physiological $\mathrm{pH}$. In their thiolate form, cysteines can easily react with partially reduced species, such as $\mathrm{H}_{2} \mathrm{O}_{2}$ or $\mathrm{NO}_{\text {to }}$ form $S$ hydroxylated or $S$-nitrosylated derivatives, respectively. Such oxidized protein thiols are unstable and tend to react with reduced glutathione (GSH), or with other thiols (e.g. free cysteine or protein sulphydryls, not indicated in the figure), which leads to the formation of a disulfide bridge and the generation of a more stable, but still reversible, $S$-glutathionylated adduct (shown on the right). Hydrogen peroxide and NO can also react directly with GSH to become reduced, but without affecting the redox state of protein thiols. GSH-dependent $\mathrm{H}_{2} \mathrm{O}_{2}$ reduction is catalyzed by glutathione peroxidase ( $\mathrm{GPx}$ ) with the concomitant production of glutathione disulfide (GSSG). Conversely, NO spontaneously reacts with GSH to form $S$-nitrosoglutathione (GSNO). $S$-nitrosoglutathione is in equilibrium with protein nitrosothiols through trans-nitrosylation reactions, and is fully reduced to $\mathrm{NH}_{3}$ and GSSG through the NADH-dependent reaction catalyzed by GSNO reductase (GSNOR). GPx and GSNOR both indirectly impact the total level of the reversibly oxidized proteins by directly regulating the concentration of $\mathrm{H}_{2} \mathrm{O}_{2}$ and $\mathrm{GSNO}$.

co-workers suggest that exposure to $\mathrm{H}_{2} \mathrm{O}_{2}$ results in the oxidation of cysteine residues of the $\alpha$ - and $\beta$-subunits of AMPK, which appears to be sufficient to increase its kinase activity (Zmijewski et al., 2010). They proposed that mutation of Cys299 of AMPK decreases its $\mathrm{H}_{2} \mathrm{O}_{2}$-mediated activation, whereas mutation of Cys304 entirely prevents it, suggesting that these two thiols are involved in the redox control of AMPK activity. In accordance with these observations, oxidative modifications of AMPK induce an allosteric rearrangement of the AMPK $\alpha \beta \gamma$ heterotrimer, thereby facilitating AMP-mediated activation of the kinase domain (Fig. 3). Nevertheless, also in this case, no measurement of adenylate activity was provided, leaving the discussion open for a possible redox dependency of AMPK.

\section{Regulation of AMPK by RNS}

Similar to ROS, NO and RNS deriving from it such as peroxynitrite $\left(\mathrm{ONOO}^{-}\right)$have been implicated in AMPK activation (see below). RNS-dependent stimulation of phosphorylation by AMPK is mainly related to the ability of NO to modulate the mitochondrial electron transport chain, and to negatively affect mitochondrial ATP production (Piantadosi, 2011). Indeed, nanomolar levels of NO are able to induce a selective and reversible inhibition of cytochrome c oxidase through the formation of a nitrosyl-heme complex containing the reduced form of the cytochrome a3, whereas higher concentrations of RNS can induce $S$-nitrosylation of cysteines, or nitration of tyrosine residues of virtually all mitochondrial complexes (Almeida et al., 2005; Moncada and Bolaños, 2006).

Growing evidence of the past few years also points to the ability of NO to activate AMPK independently of mitochondrial failure. For example, Zhang and colleagues demonstrated that NO acts as an endogenous activator of AMPK in endothelial cells by increasing $\mathrm{Ca}^{2+}$ levels through the activation of soluble guanylyl cyclase, the canonical target of NO. NO-induced $\mathrm{Ca}^{2+}$ increase elicits CaMKK $\beta$-mediated AMPK activation (Zhang et al., 2008). This signaling pathway might be predominant under resting conditions, because it allows regulation of physiological functions related to vascular homeostasis (Zhang et al., 2008). Conversely, in pathological circumstances characterized by overproduction of $\mathrm{ONOO}^{-}$, it has been reported that $\mathrm{ONOO}^{-}$activates protein kinase

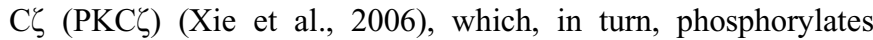
LKB1, leading to the activation of AMPK and the energy-restoring pathways downstream (Zou et al., 2004; An et al., 2007). Interestingly, the endothelial isoform of NO synthase (eNOS) is activated by AMPK through the phosphorylation of Ser1177 (Chen et al., 1999), indicating that AMPK is also able to regulate RNS levels by inducing NO production. Therefore, an increase in AMPK activity under different physiological and pathological conditions (e.g. stimulation of vascular endothelial growth factor) can lead to an increase in NO synthesis by eNOS (Reihill et al., 2007; Levine et al., 2007), which, in turn, could further increase its production through the AMPK positive-feedback loop. Importantly, in $\mathrm{Nos}^{-/-}$mice, the AMPK-activating drug metformin (Calvert et al., 2008) has no effect on AMPK in endothelial cells, emphasizing the role of endogenous NO in activating AMPK and its subsequent consequences on bioenergetic metabolism (Fig. 3).

\section{S-nitrosylation as a possible regulatory process of AMPK activity}

The impact of NO on cellular metabolism is not only regulated at the level of NO synthesis, but also through removal of its 


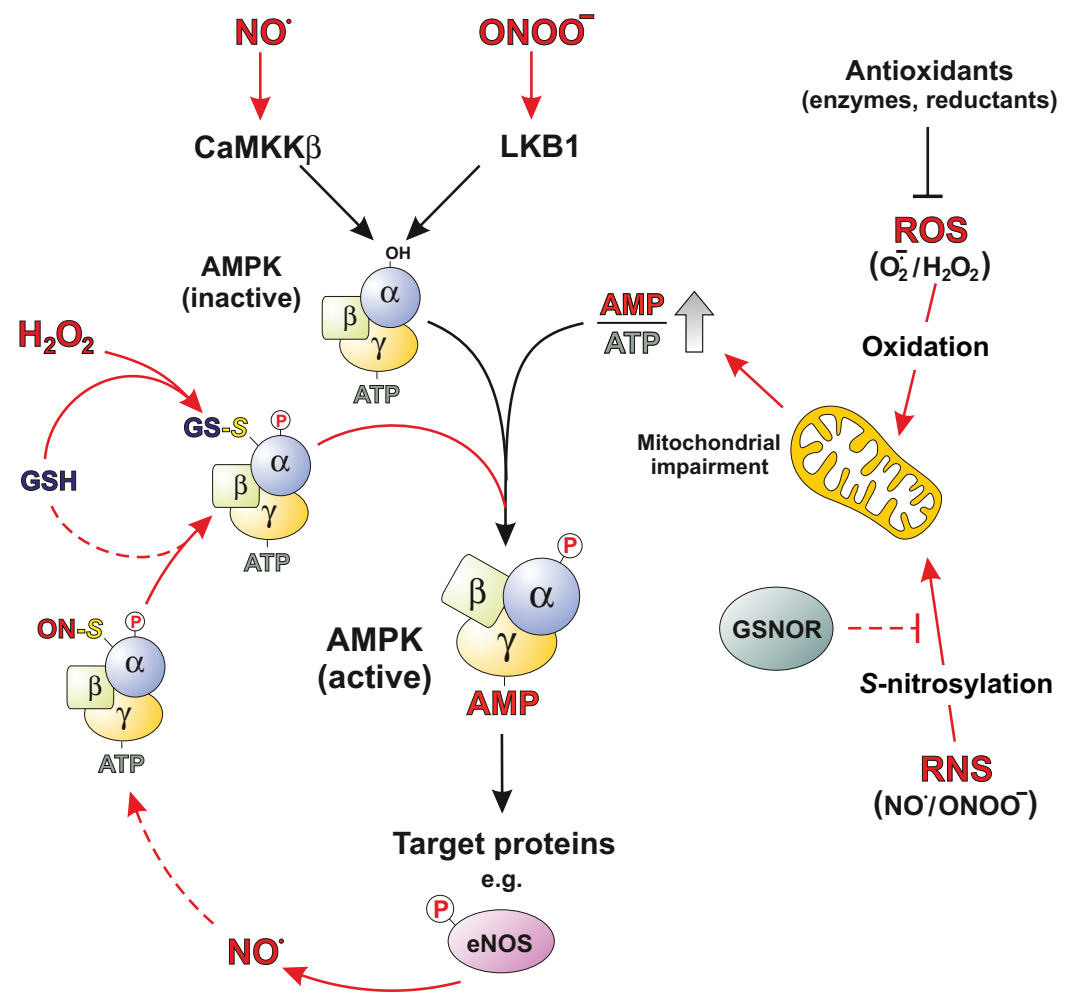

Fig. 3. AMPK at the crossroad of metabolic and nitroxidative networks. The canonical activation of AMPK relies on a double stimulus; its binding to AMP, whose relative concentration to ATP is increased under metabolic stress, and the phosphorylation of its Thr172 residue, which is mediated by the upstream kinases liver kinase B1 (LKB1) and $\mathrm{Ca}^{2+}$-calmodulin-dependent kinase kinase $\beta(\mathrm{CaMKK} \beta)$. In addition to this pathway, nitroxidative stress can also activate AMPK, with $\mathrm{NO}$ and peroxinitrite $\left(\mathrm{ONOO}^{-}\right)$, which can then activate CaMKK $\beta$ and LKB1, respectively. ROS and RNS can act as positive regulators of AMPK activity by means of the induction of oxidation or $S$ nitrosylation reactions at the level of mitochondrial complexes, which finally results in a decrease of the ratio between AMP and ATP. Conversely, GSNOR could negatively regulate AMPK activation and downstream cell responses by decreasing mitochondrial $S$-nitrosothiols, but this has not yet been demonstrated. AMPK could be directly activated by $\mathrm{H}_{2} \mathrm{O}_{2}$ and $\mathrm{NO}$ through the reversible oxidation of cysteine residues. In the presence of GSH, $S$-glutathionylated adduct can be formed, which has been suggested to prime AMPK for phosphorylation. Among protein targets undergoing phosphorylation and activation by AMPK is endothelial nitric oxide synthase (eNOS, shown in the bottom). This induces NO production, thereby generating a positive-feedback loop with NO both directly and through CaMKK $\beta$ (see above). Black arrows, metabolic state-dependent routes; red arrows, nitroxidative stress-responsive routes; dashed lines, hypothetical pathways. derivatives, such as $S$-nitrosothiols (Fig. 2). In particular, $S$ nitrosoglutathione (GSNO) reductase (GSNOR) has a pivotal role in suppressing NO bioactivity by degrading GSNO and reducing the levels of $S$-nitrosylated proteins (Liu et al., 2001; Foster et al., 2009). Although the link between AMPK and eNOS is well established, no evidence has been provided so far for the putative relationship between AMPK and GSNOR activity. Given that nitration and/or $S$-nitrosylation of mitochondrial respiratory complexes accounts for impaired ATP synthesis as discussed above, inhibition of GSNOR could increase the ratio between AMP and ATP, and then activate AMPK activation. Although nitrosylative modifications of AMPK have been never described, it is conceivable that an increase of nitrosylating equivalents, under conditions of inhibited GSNOR, can promote $S$ nitrosylation of Cys299 and Cys304 of the AMPK $\alpha$-subunit, the same cysteine residues that are $S$-glutathionylated by $\mathrm{H}_{2} \mathrm{O}_{2}$ (Fig. 3). In this context, it has been recently demonstrated that, in endothelial cells, AMPK is phosphorylated upon treatment with different NO donors, and, once activated, phosphorylates IкB kinase (IKK $\beta$ ) (Bess et al., 2011). This leads to suppression of $\mathrm{NF}-\kappa \mathrm{B}$, and importantly, has been suggested to have a role in the anti-inflammatory response of NO (Bess et al., 2011). By contrast, HeLa cells and neurons treated with the same NO donors show a decrease in the basal levels of phosphorylated AMPK (Sarkar et al., 2011). Intriguingly, the authors demonstrate that AMPK phosphorylation relies on the upstream activation of IKK $\beta$ - the same kinase thought to be a target of AMPK in the study by Bess and colleagues - a response that is entirely dependent on the generation of $S$-nitrosothiols (Sarkar et al., 2011). Although both studies indicate that AMPK phosphorylation is intimately linked to nitroxidative conditions, they also present potentially conflicting data, illustrating that the role of $S$-nitrosylation in modulating AMPK function is still very much an issue of active debate.

\section{Cellular outcomes in response to metabolic nitroxidative stress: from survival to death}

To overcome metabolic stress induced by pro-oxidant conditions, AMPK regulates the activity of key enzymes involved in cell metabolism to guarantee bioenergetics reprogramming, and drives cell fate by regulating signaling proteins to induce survival or cell death by different mechanisms, such as autophagy and apoptosis (Steinberg and Kemp, 2009), as discussed below.

\section{Redox modulation of AMPK activity in autophagy}

In addition to promoting the activity of catabolic enzymes and switching off anabolic pathways, AMPK also maintains cell viability under prolonged bioenergetic impairment by inducing autophagy (Mihaylova and Shaw, 2011) (Fig. 4). Autophagy is the major regulated catabolic mechanism used by eukaryotic cells to degrade proteins and organelles (Kroemer et al., 2010). It involves the formation of cytosolic double-membrane vesicles, called autophagosomes, which sequester portions of the cytoplasm that are then fused with lysosomes and degraded. Autophagy has a role in the maintenance of tissue homeostasis and in the response to environmental stresses; moreover, this process is often deregulated in various human diseases, such as neurodegeneration and cancer (Cecconi and Levine, 2008). Growing evidence supports the idea that redox imbalance affects autophagy, especially during autophagosome elongation (Filomeni et al., 2010a). Nonetheless, protease autophagy-related gene 4 (Atg4) remains the sole example of an autophagic protein whose redox regulation has been demonstrated to be necessary for the progression of autophagy (Scherz-Shouval et al., 2007). 


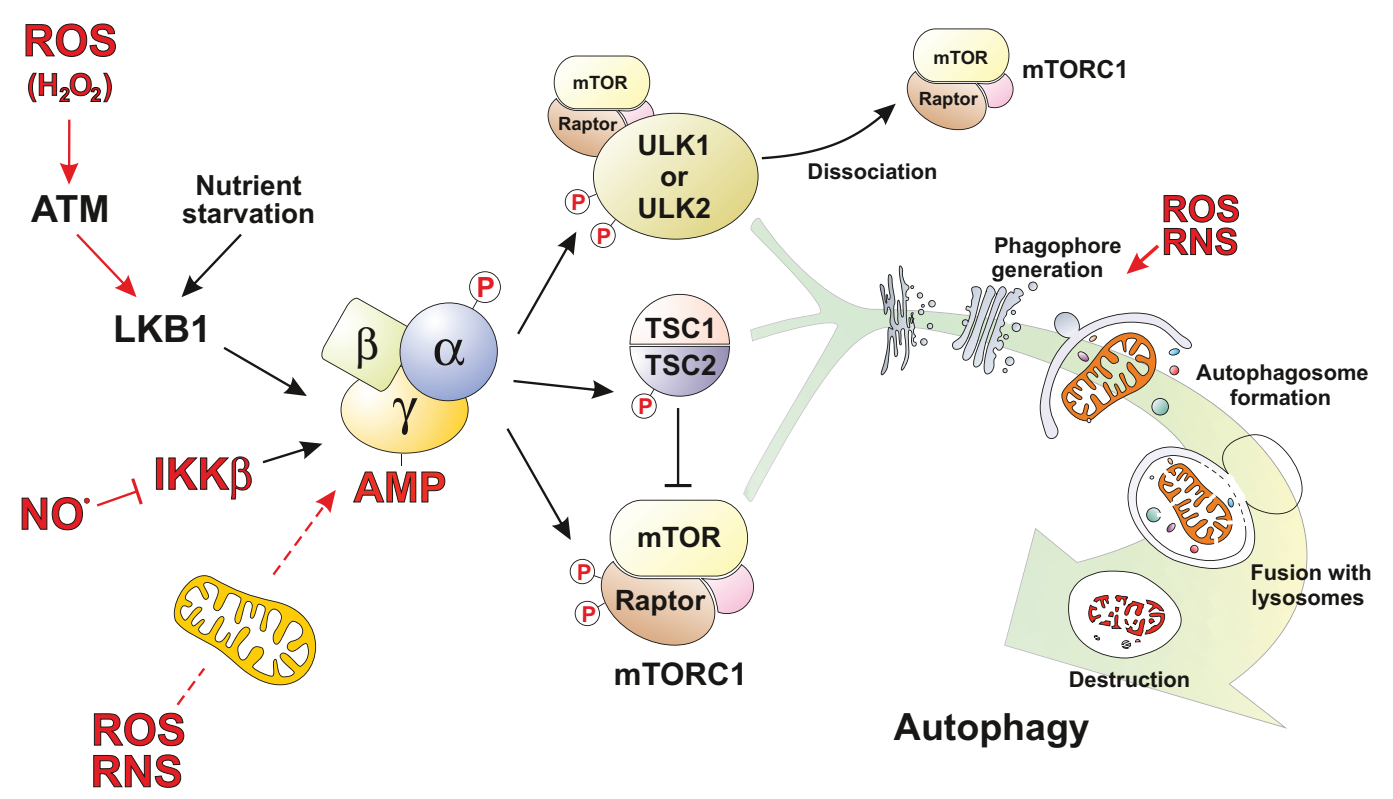

Fig. 4. Involvement of AMPK in autophagic signaling. AMPK can elicit autophagy steps by directly phosphorylating different protein substrates involved in its initiation phases (see schematic overview of autophagy on the left), such as TSC2, two sites on Raptor and two sites on ULK1 or ULK2. These phosphorylation events are the result of either bioenergetic alterations (black arrows) or nitroxidative stress (red arrows) and stimulate autophagy steps. In particular, AMPK is modulated positively by $\mathrm{H}_{2} \mathrm{O}_{2}$, through activation of the ATM-LKB1 phosphorylation cascade, and negatively by NO, through the direct inhibition of IKK $\beta$. Because AMPK has been shown to be activated upon nitroxidative-stress-mediated mitochondrial injury, a putative induction of autophagy through ROS- or RNSresponsive pathways is possible. $S \mathrm{NOs}, S$-nitrosothiols; dashed lines, hypothetical pathways.

In the past few years, it has been revealed that the main route by which AMPK promotes autophagy is through inactivation of the nutrient-sensitive mammalian target of rapamycin (mTOR) complex I (mTORC1), a complex in which mTOR is bound to its regulatory protein Raptor. This inactivation allows the dissociation of mTORC1 from the complex with the autophagy initiator UNC51-like kinase 1 or 2 (ULK1 or ULK2) (Kroemer et al., 2010), either by a direct phosphorylation of the mTOR negative regulator tuberous sclerosis complex 2 (TSC2) at Ser1387 (Inoki et al., 2006) or by the phosphorylation of Raptor at Ser722 and Ser792 (Gwinn et al., 2008) (Fig. 4).

AMPK can activate the autophagic machinery under severe pro-oxidant conditions. For instance, $\mathrm{H}_{2} \mathrm{O}_{2}$ activates ataxiatelangiectasia mutated (ATM) in the cytoplasm, thus suppressing mTOR activity through stimulation of the ATM-LKB1-AMPKTSC2 phosphorylation signaling cascade (Alexander et al., 2010) (Fig. 4). Moreover, because AMPK can activate ULK1 by direct phosphorylation of Ser317 and Ser777 (Egan et al., 2011; Kim et al., 2011) (Fig. 4), it can be speculated that ROS can sustain the activation of the autophagic machinery through the AMPKULK1 signaling axis, independent of TSC2-mediated inhibition of mTORC1. Although the established ability of ROS to elicit autophagy via AMPK and of NO to induce bioenergetic stress and activate AMPK, only one piece of evidence has been provided thus far in vitro supporting a causal relationship between nitrosative stress and autophagy (Sarkar et al., 2011). Here, treatment with NO donors results in the suppression of AMPK phosphorylation, thereby inhibiting the autophagic machinery (Fig. 4). Although this has been shown to rely completely on $S$-nitrosylation reactions, no evidence that such modification occurs directly on AMPK has been provided (Sarkar et al., 2011). These data indicate that NO acts as a modulator of autophagy through pathways involving AMPK in some way; however physiological in vivo systems need to be considered in the future to better evaluate the relationship between $S$ nitrosothiols and AMPK in autophagy.

\section{Redox modulation of AMPK activity in apoptosis}

Although AMPK is mainly considered to be a pro-survival kinase, its involvement in the induction of cell death has also been demonstrated, mostly in conditions of its sustained activation (Ronnett et al., 2009; Weisová et al., 2011) (Fig. 5). For instance, it has been shown that prolonged AMPK activation can result in the upregulation of the pro-apoptotic $\mathrm{BH} 3$-only protein $\mathrm{BIM}$ in neurons (Concannon et al., 2010). Even though the underlying molecular mechanism(s) has not been identified, Weisová and colleagues suggested that the engagement of the AMPK-FOXO3A signaling axis might be responsible for the induction of BIM (Weisová et al., 2011). This assumption is based on the ability of the transcription factor FOXO3A to transactivate the BIM gene promoter in neurons (Biswas et al., 2007), and on the ability of AMPK to down-modulate the activity of the protein kinase B (also known as AKT) (Tzatsos and Tsichlis, 2007), which in turn, is responsible for phosphorylation-mediated inactivation of FOXO3A (Brunet et al., 1999). Similarly, it has been reported that, upon severe reduction in ATP levels, AMPK induces cell death of rat insulinoma INS1 through transcriptional activation of the pro-apoptotic BH3-only protein BMF (Kilbride et al., 2010). Moreover, the large amount of data illustrating the ability of AMPK to activate p53 upon glucose deprivation and to induce its pro-apoptotic ability (Okoshi et al., 2008), lends further support to the hypothesis that enduring bioenergetic crisis can be a crucial factor that couples energy stress with apoptosis induction. AMPK can also interact with the mitogen-activated protein kinase 


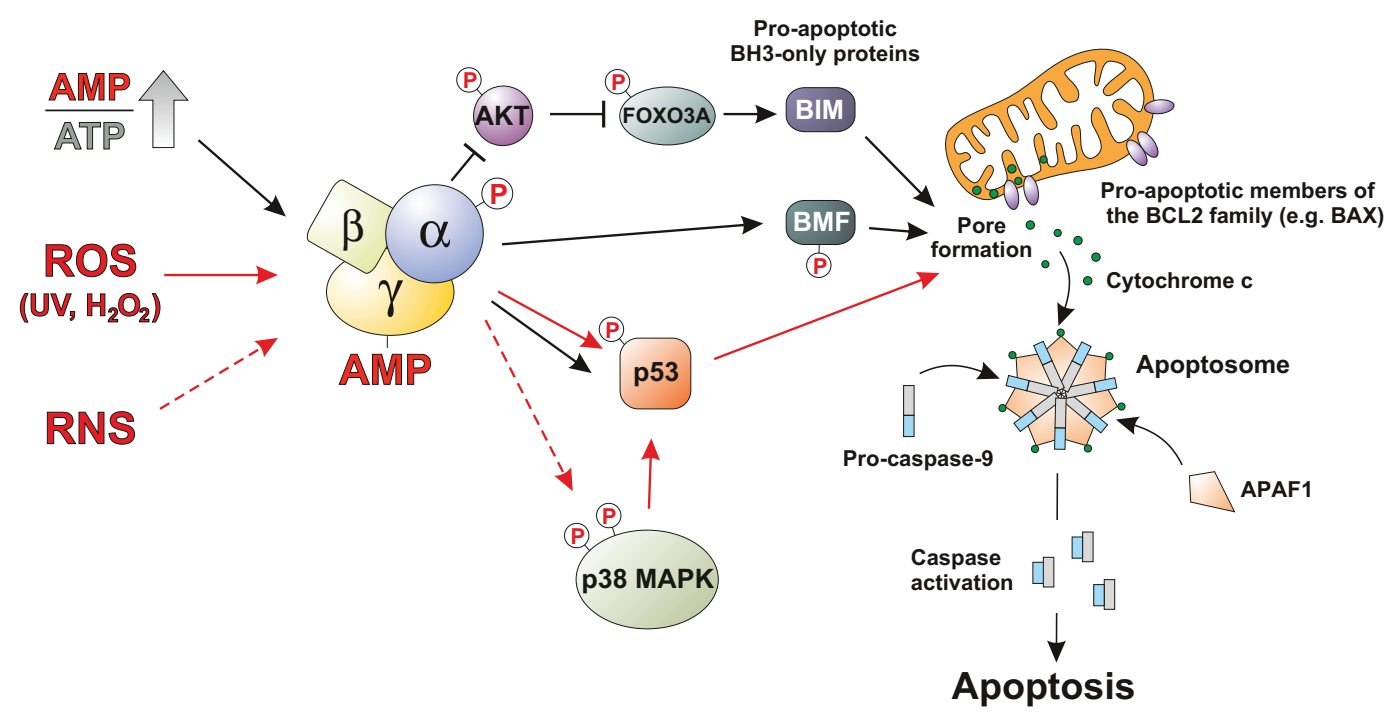

Fig. 5. Involvement of AMPK in apoptotic signaling. Severe metabolic alterations (black arrows) and nitroxidative conditions (red arrows) can be transduced into an apoptotic response by activation of AMPK. Several effectors downstream of AMPK have been found that affect the release of cytochrome $\mathrm{c}$ from mitochondria, thereby allowing the apoptosome and caspases to be activated (see illustrations on the right for a schematic overview of apoptosis). AMPK has been implicated in the phospho-activation of the pro-apoptotic BH3-only proteins either through direct phosphorylation, for example of BMF or by phosphorylative inactivation of AKT-FOXO3A pathway, whose occurrence has been suggested to induce the translocation of Bim to mitochondria. AMPK has been also been shown to phospho-activate p53 and p38 MAPK, thereby further eliciting apoptotic response. However, there is no direct evidence that AMPK phosphorylates p38 MAPK residues. 533 phosphorylation can be directly catalyzed by AMPK, or driven by phosphorylated p38 MAPK itself, thereby generating a positive-feedback loop that enhances the pro-apoptotic action of $\mathrm{p} 53$. Dashed lines, hypothetical pathways.

(MAPK) signaling cascade, in particular through activation of $\mathrm{p} 38$ MAPK (also known as MAPK14), to mediate apoptosis that is elicited by both energetic imbalance and pro-oxidant conditions, such as treatment with $\mathrm{H}_{2} \mathrm{O}_{2}$ or UV (Cao et al., 2008), exposure to flavonoid-generated ROS (Lee et al., 2010) or to mitochondrial toxins (Filomeni et al., 2011) (Fig. 5). It is noteworthy that, although AMPK has been established to be an upstream regulator of $\mathrm{p} 38 \mathrm{MAPK}$, there is no compelling evidence that this regulation occurs by direct phosphorylation. Indeed, AMPK elicits recruitment of $\mathrm{p} 38$ MAPK to transforming growth factor TGF $\beta$ activated protein kinase-1-binding protein 1 (TAB1), a scaffold protein that promotes $\mathrm{p} 38$ MAPK auto-phosphorylation ( $\mathrm{Li}$ et al., 2005). In summary, AMPK is activated to drive either cell death or survival, but intriguingly, some of the AMPK targets needed to propagate this signal through phosphorylation cascades (e.g. p38 MAPK and the Jun N-terminal kinase JNK), have been implicated in both processes. This suggests that other intermediate modulators or interactors, which are able to determine whether cell death or survival pathways predominate, remain to be identified.

\section{Clinical opportunities for AMPK: from cancer to neurodegeneration}

The ability of AMPK to concomitantly regulate multiple bioenergetic pathways and cell responses to redox changes renders it a feasible therapeutic target for the treatment of redox- and metabolic-based diseases (Viollet et al., 2007; Zhou et al., 2009), including cancer and neurodegenerative disorders as discussed below.

\section{AMPK as a target in anti-cancer therapies}

Recently, there has been renewed interest in the potential use of AMPK for cancer prevention and treatment (Fogarty and Hardie, 2010). Cancer cells differ from untransformed cells after a plethora of molecular changes, many of which converge into metabolic and redox reprogramming that aims to sustain their faster rate of growth and proliferation (Kroemer and Pouyssegur, 2008). Well-established hallmarks of tumor biology have been described, such as the metabolic shift in cancer cells from oxidative phosphorylation to glycolysis under conditions of high oxygen tension (the so-called aerobic glycolysis, or Warburg effect), and non-physiological alterations of the intracellular redox state as a result of the increased production of NO and ROS (Tennant et al., 2010; Trachootham et al., 2009). Supporting the tight link between tumorigenesis and metabolic oxidative changes, AMPK has been implicated in cancer development. Indeed, germline mutations in the LKB1 tumor suppressor gene, the main activator of AMPK, have been identified as the genetic cause of the Peutz-Jeghers syndrome, an inherited predisposition to cancer characterized by the development of intestinal hamartomatous polyps (Hemminki, 1999), suggesting that impaired AMPK activation could promote and sustain cancerogenesis. The observation that tumors with reduced levels of AMPK phosphorylation are indicative of poor prognostic outcome (Hadad et al., 2009) suggests that loss of AMPK activity could make tumor cells more aggressive. It has been demonstrated that several anti-diabetic drugs, such as metformin and the thienopyridone A769662, delay the growth of spontaneous and carcinogen-induced tumors in an AMPK-responsive manner through downregulation of mTORC1 signaling (Anisimov et al., 2005; Huang et al., 2008). Interestingly, epidemiological studies indicate that patients with type II diabetes who have been treated with metformin are found to have a significantly reduced risk of developing cancer (Bowker et al., 2006; Monami et al., 2011). Overall, these data point towards a tumor-suppressor role of AMPK and it has been hypothesized that its activation might represent a novel strategy for preventing cancer (Fruman and Edinger, 2008). 
In addition to studies that reveal the ability of AMPK activators to act as anticancer agents, recent data suggests that AMPK activation also represents a novel and feasible therapeutic strategy for cancer treatment. For example, chemotherapeutics have been developed that selectively affect the growth of tumor cells and their viability by promoting AMPK activation. Particularly, the methylating drug temozolomide and the cellpermeable C6 ceramide have been shown to induce apoptosis in primary cultured human glioblastoma cells and to sensitize multiple cancer cell lines to doxorubicin by eliciting AMPK activation (Ji et al., 2010; Zhang et al., 2010). Furthermore, the observations that the phosphatidylinositol ether lipid analogues (PIAs) (Memmott et al., 2008), the isatin-Schiff base copper(II) complexes (Filomeni et al., 2009; Filomeni et al., 2011) and some nutraceuticals (e.g. curcumin and selenium) (Hwang et al., 2006; Pan et al., 2008), are able to cause death in various cancer cell lines by triggering AMPK-dependent apoptosis, further highlight the potential role of AMPK as a promising target for drugs reversing, suppressing or preventing carcinogenic progression. Nevertheless, it is worthwhile noting that, as observed for most anticancer drugs, AMPK activators might also cause detrimental side effects. Indeed, AMPK activation by anticancer compounds has been shown to promote tumor cell survival instead of cell death owing to activation of AMPK-mediated autophagic pathways (see below). Several lines of evidence show that autophagy activation enables long-term survival, keeping cancer cells alive when limited angiogenesis leads to nutrient deprivation and hypoxia. AMPK-mediated autophagy appears to enhance the resistance of cancer cells to chemotherapeutic agents (e.g. cisplatin), and to naturally occurring molecules (e.g. polyphenols), which have been considered to be promising anticancer drugs owing to their ability to induce metabolic oxidative stress (Harhaji-Trajkovic et al., 2009; Filomeni et al., 2010b). In light of these results, it is reasonable to consider that although targeting AMPK remains a feasible approach to selectively kill tumor cells, the possible activation of AMPKmediated pathways mediating tumor resistance, such as autophagy, should be taken into account.

\section{Dual role of AMPK in neurodegenerative disease}

Although AMPK-mediated autophagy might represent the Achilles' heel of some chemotherapeutic approaches for the treatment of proliferative diseases as discussed above (Bhutia et al., 2010; Yang et al., 2010; Rosenfeldt, and Ryan, 2011), it could be beneficial in non-renewing tissues, such as neurons (Mariño et al., 2011). Several observations demonstrate that AMPK-mediated autophagy has a cytoprotective effect in some models of neurodegenerative disease, such as Huntington's and Alzheimer's diseases, because it contributes to the removal of aggregate-prone mutant proteins and to sustaining neuronal bioenergetics, which is negatively affected under neurodegenerative-associated pro-oxidant conditions (Spencer et al., 2009; Wong and Cuervo, 2010; Underwood et al., 2010; Vingtdeux et al., 2011; Vingtdeux et al., 2010). In support of this assumption, it has been recently suggested that NO-mediated inhibition of autophagy, which is associated with AMPK dephosphorylation, gives rise to a significant increase in huntingtin-containing aggregates in neurons that express the mutant form of the protein (Sarkar et al., 2011). However, although short-term activation of AMPK could mediate an adaptive neuronal quality control through induction of the autophagic machinery, its persistent activation is not beneficial for neurons (Ronnett et al., 2009). In fact, several in vitro studies indicate that activation of AMPK over longer periods is harmful. Indeed, the pharmacological activator of AMPK, 5aminoimidazole-4-carboxamide-1- $\beta$-D-ribofuranoside (AICAR), was found to be pro-apoptotic in several human and mouse neuronal cell lines (Garcia-Gil et al., 2003). Moreover, it has been shown that metformin significantly increases the in vivo generation of $\beta$-amyloid peptide, which has a crucial role in the pathogenesis of Alzheimer's disease (Chen, Y. et al., 2009). Likewise, in vivo studies suggest that AMPK activation that occurs after cerebral ischemia is detrimental to neuronal survival. For example, genetic and pharmacological inhibition of AMPK under these conditions reduces stroke damage (McCullough et al., 2005; Li et al., 2007), reinforcing the hypothesis that an excessive and sustained activation of neuronal AMPK when oxygen and glucose substrates are lacking might induce a 'metabolic-failurelike' state leading to neuronal demise.

\section{Conclusions and Perspectives}

In addition to the signaling network upstream of AMPK activation, which senses and responds to metabolic alterations in a concerted manner, a growing number of observations have recently indicated that AMPK can be activated even upon nitroxidative unbalance. Compelling evidence for whether this activation is direct, exclusively through cysteine oxidation without perturbing adenylate energy charge, or indirect, through the impairment of mitochondrial ATP-generating machinery, is still limited. However, these findings, and the novel concepts arising from them, reinforce the concept of the tight link between cellular (bio)energetics and redox status. They also open new perspectives with regard to the wide impact that AMPK can have on cellular processes that rely upon nitroxidative unbalance, and ultimately, on the role of AMPK in human pathophysiology. Indeed, AMPK can activate protein targets that are not restricted to metabolism, but are also implicated in driving signaling pathways leading to diverse cellular outcomes, such as apoptosis, proliferation and autophagy. Along this line, the possible use of drugs that modulate AMPK activity represents a clinical opportunity for treatment of diseases that are tightly related to metabolic dysfunction, and pathological states, such as cancer and neurodegeneration.

\section{Funding}

This work was partially supported by grants from Ministero della Salute, Progetto Giovani Ricercatori 2008 [grant number GR-20081138121]; Italian Association for Cancer Research (AIRC) [grant number IG 10636]; and the Ministero dell'Università e della Ricerca (MIUR)

\section{References}

Alexander, A., Cai, S. L., Kim, J., Nanez, A., Sahin, M., MacLean, K. H., Inoki, K., Guan, K. L., Shen, J., Person, M. D. et al. (2010). ATM signals to TSC2 in the cytoplasm to regulate mTORC1 in response to ROS. Proc. Natl. Acad. Sci. USA 107, 4153-4158.

Almeida, A., Cidad, P., Delgado-Esteban, M., Fernández, E., García-Nogales, P. and Bolaños, J. P. (2005). Inhibition of mitochondrial respiration by nitric oxide: its role in glucose metabolism and neuroprotection. J. Neurosci. Res. 79, 166-171.

An, Z., Wang, H., Song, P., Zhang, M., Geng, X. and Zou, M. H. (2007). Nicotineinduced activation of AMP-activated protein kinase inhibits fatty acid synthase in 3T3L1 adipocytes: a role for oxidant stress. J. Biol. Chem. 282, 26793-26801.

Anisimov, V. N., Berstein, L. M., Egormin, P. A., Piskunova, T. S., Popovich, I. G., Zabezhinski, M. A., Kovalenko, I. G., Poroshina, T. E., Semenchenko, A. V., Provinciali, M. et al. (2005). Effect of metformin on life span and on the 
development of spontaneous mammary tumors in HER-2/neu transgenic mice. Exp. Gerontol. 40, 685-693.

Ataullakhanov, F. I. and Vitvitsky, V. M. (2002). What determines the intracellular ATP concentration. Biosci. Rep. 22, 501-511.

Atkinson, D. E. (1968). The energy charge of the adenylate pool as a regulatory parameter. Interaction with feedback modifiers. Biochemistry 7, 4030-4034.

Atkinson, D. E. (1970). Adenine nucleotides as universal stoichiometric metabolic coupling agents. Adv. Enzyme Regul. 9, 207-219.

Barnes, K., Ingram, J. C., Porras, O. H., Barros, L. F., Hudson, E. R., Fryer, L. G., Foufelle, F., Carling, D., Hardie, D. G. and Baldwin, S. A. (2002). Activation of GLUT1 by metabolic and osmotic stress: potential involvement of AMP-activated protein kinase (AMPK). J. Cell Sci. 115, 2433-2442.

Bess, E., Fisslthaler, B., Frömel, T. and Fleming, I. (2011). Nitric oxide-induced activation of the AMP-activated protein kinase $\alpha 2$ subunit attenuates IкB kinase activity and inflammatory responses in endothelial cells. PLOS ONE 6, e20848.

Bhutia, S. K., Kegelman, T. P., Das, S. K., Azab, B., Su, Z. Z., Lee, S. G., Sarkar, D. and Fisher, P. B. (2010). Astrocyte elevated gene-1 induces protective autophagy. Proc. Natl. Acad. Sci. USA 107, 22243-22248.

Biswas, S. C., Shi, Y., Sproul, A. and Greene, L. A. (2007). Pro-apoptotic Bim induction in response to nerve growth factor deprivation requires simultaneous activation of three different death signaling pathways. J. Biol. Chem. 282, 2936829374

Bowker, S. L., Majumdar, S. R., Veugelers, P. and Johnson, J. A. (2006). Increased cancer-related mortality for patients with type 2 diabetes who use sulfonylureas or insulin. Diabetes Care 29, 254-258.

Brunet, A., Bonni, A., Zigmond, M. J., Lin, M. Z., Juo, P., Hu, L. S., Anderson, M. J., Arden, K. C., Blenis, J. and Greenberg, M. E. (1999). Akt promotes cell survival by phosphorylating and inhibiting a Forkhead transcription factor. Cell 96, 857-868

Calvert, J. W., Gundewar, S., Jha, S., Greer, J. J., Bestermann, W. H., Tian, R. and Lefer, D. J. (2008). Acute metformin therapy confers cardioprotection against myocardial infarction via AMPK-eNOS-mediated signaling. Diabetes 57, 696-705.

Cao, C., Lu, S., Kivlin, R., Wallin, B., Card, E., Bagdasarian, A., Tamakloe, T., Chu, W. M., Guan, K. L. and Wan, Y. (2008). AMP-activated protein kinase contributes to UV- and $\mathrm{H}_{2} \mathrm{O}_{2}$-induced apoptosis in human skin keratinocytes. J. Biol. Chem. 283, 28897-28908.

Cecconi, F. and Levine, B. (2008). The role of autophagy in mammalian development: cell makeover rather than cell death. Dev. Cell 15, 344-357.

Chen, L., Jiao, Z. H., Zheng, L. S., Zhang, Y. Y., Xie, S. T., Wang, Z. X. and Wu, J. W. (2009). Structural insight into the autoinhibition mechanism of AMP-activated protein kinase. Nature 459, 1146-1149.

Chen, Y., Zhou, K., Wang, R., Liu, Y., Kwak, Y. D., Ma, T., Thompson, R. C., Zhao, Y., Smith, L., Gasparini, L. et al. (2009). Antidiabetic drug metformin (GlucophageR) increases biogenesis of Alzheimer's amyloid peptides via upregulating BACE1 transcription. Proc. Natl. Acad. Sci. USA 106, 3907-3912.

Chen, Z. P., Mitchelhill, K. I., Michell, B. J., Stapleton, D., Rodriguez-Crespo, I., Witters, L. A., Power, D. A., Ortiz de Montellano, P. R. and Kemp, B. E. (1999). AMP-activated protein kinase phosphorylation of endothelial NO synthase. FEBS Lett. 443, 285-289.

Choi, S. L., Kim, S. J., Lee, K. T., Kim, J., Mu, J., Birnbaum, M. J., Soo Kim, S. and Ha, J. (2001). The regulation of AMP-activated protein kinase by $\mathrm{H}(2) \mathrm{O}(2)$. Biochem. Biophys. Res. Commun. 287, 92-97.

Concannon, C. G., Tuffy, L. P., Weisová, P., Bonner, H. P., Dávila, D., Bonner, C., Devocelle, M. C., Strasser, A., Ward, M. W. and Prehn, J. H. (2010). AMP kinasemediated activation of the BH3-only protein Bim couples energy depletion to stressinduced apoptosis. J. Cell Biol. 189, 83-94.

Crute, B. E., Seefeld, K., Gamble, J., Kemp, B. E. and Witters, L. A. (1998). Functional domains of the alphal catalytic subunit of the AMP-activated protein kinase. J. Biol. Chem. 273, 35347-35354.

Egan, D. F., Shackelford, D. B., Mihaylova, M. M., Gelino, S., Kohnz, R. A., Mair, W., Vasquez, D. S., Joshi, A., Gwinn, D. M., Taylor, R. et al. (2011). Phosphorylation of ULK1 (hATG1) by AMP-activated protein kinase connects energy sensing to mitophagy. Science 331, 456-461.

Emerling, B. M., Weinberg, F., Snyder, C., Burgess, Z., Mutlu, G. M., Viollet, B., Budinger, G. R. and Chandel, N. S. (2009). Hypoxic activation of AMPK is dependent on mitochondrial ROS but independent of an increase in AMP/ATP ratio. Free Radic. Biol. Med. 46, 1386-1391.

Filomeni, G., Piccirillo, S., Graziani, I., Cardaci, S., Da Costa Ferreira, A. M., Rotilio, G. and Ciriolo, M. R. (2009). The isatin-Schiff base copper(II) complex $\mathrm{Cu}$ (isaepy) 2 acts as delocalized lipophilic cation, yields widespread mitochondrial oxidative damage and induces AMP-activated protein kinase-dependent apoptosis. Carcinogenesis 30, 1115-1124.

Filomeni, G., Desideri, E., Cardaci, S., Rotilio, G. and Ciriolo, M. R. (2010a). Under the ROS...thiol network is the principal suspect for autophagy commitment. Autophagy 6, 999-1005.

Filomeni, G., Desideri, E., Cardaci, S., Graziani, I., Piccirillo, S., Rotilio, G. and Ciriolo, M. R. (2010b). Carcinoma cells activate AMP-activated protein kinasedependent autophagy as survival response to kaempferol-mediated energetic impairment. Autophagy 6, 202-216.

Filomeni, G., Cardaci, S., Da Costa Ferreira, A. M., Rotilio, G. and Ciriolo, M. R. (2011). Metabolic oxidative stress elicited by the copper(II) complex [Cu(isaepy)2] triggers apoptosis in SH-SY5Y cells through the induction of the AMP-activated protein kinase/p38MAPK/p53 signalling axis: evidence for a combined use with 3bromopyruvate in neuroblastoma treatment. Biochem. J. 437, 443-453.

Fogarty, S. and Hardie, D. G. (2010). Development of protein kinase activators: AMPK as a target in metabolic disorders and cancer. Biochim. Biophys. Acta 1804, 581-591.

Foster, M. W., Hess, D. T. and Stamler, J. S. (2009). Protein S-nitrosylation in health and disease: a current perspective. Trends Mol. Med. 15, 391-404.

Fruman, D. A. and Edinger, A. L. (2008). Cancer therapy: staying current with AMPK. Biochem. J. 412, e3-e5.

Garcia-Gil, M., Pesi, R., Perna, S., Allegrini, S., Giannecchini, M., Camici, M. and Tozzi, M. G. (2003). 5' -aminoimidazole-4-carboxamide riboside induces apoptosis in human neuroblastoma cells. Neuroscience 117, 811-820.

Ghillebert, R., Swinnen, E., Wen, J., Vandesteene, L., Ramon, M., Norga, K., Rolland, F. and Winderickx, J. (2011). The AMPK/SNF1/SnRK1 fuel gauge and energy regulator: structure, function and regulation. FEBS J. 278, 3978-3990.

Gwinn, D. M., Shackelford, D. B., Egan, D. F., Mihaylova, M. M., Mery, A., Vasquez, D. S., Turk, B. E. and Shaw, R. J. (2008). AMPK phosphorylation of raptor mediates a metabolic checkpoint. Mol. Cell 30, 214-226.

Hadad, S. M., Baker, L., Quinlan, P. R., Robertson, K. E., Bray, S. E., Thomson, G., Kellock, D., Jordan, L. B., Purdie, C. A., Hardie, D. G. et al. (2009). Histological evaluation of AMPK signalling in primary breast cancer. BMC Cancer 9, 307.

Hardie, D. G. (2007). AMP-activated/SNF1 protein kinases: conserved guardians of cellular energy. Nat. Rev. Mol. Cell Biol. 8, 774-785.

Hardie, D. G. (2011). AMP-activated protein kinase: an energy sensor that regulates all aspects of cell function. Genes Dev. 25, 1895-1908.

Hardie, D. G., Carling, D. and Gamblin, S. J. (2011). AMP-activated protein kinase: also regulated by ADP? Trends Biochem. Sci. 36, 470-477.

Harhaji-Trajkovic, L., Vilimanovich, U., Kravic-Stevovic, T., Bumbasirevic, V. and Trajkovic, V. (2009). AMPK-mediated autophagy inhibits apoptosis in cisplatintreated tumour cells. J. Cell. Mol. Med. 13, 3644-3654.

Hawley, S. A., Pan, D. A., Mustard, K. J., Ross, L., Bain, J., Edelman, A. M., Frenguelli, B. G. and Hardie, D. G. (2005). Calmodulin-dependent protein kinase kinase-beta is an alternative upstream kinase for AMP-activated protein kinase. Cell Metab. 2, 9-19.

Hawley, S. A., Ross, F. A., Chevtzoff, C., Green, K. A., Evans, A., Fogarty, S., Towler, M. C., Brown, L. J., Ogunbayo, O. A., Evans, A. M. et al. (2010). Use of cells expressing gamma subunit variants to identify diverse mechanisms of AMPK activation. Cell Metab. 11, 554-565.

Hemminki, A. (1999). The molecular basis and clinical aspects of Peutz-Jeghers syndrome. Cell. Mol. Life Sci. 55, 735-750.

Herrero-Martín, G., Høyer-Hansen, M., García-García, C., Fumarola, C., Farkas, T., López-Rivas, A. and Jäättelä, M. (2009). TAK1 activates AMPK-dependent cytoprotective autophagy in TRAIL-treated epithelial cells. EMBO J. 28, 677-685.

Huang, X., Wullschleger, S., Shpiro, N., McGuire, V. A., Sakamoto, K., Woods, Y. L., McBurnie, W., Fleming, S. and Alessi, D. R. (2008). Important role of the LKB1-AMPK pathway in suppressing tumorigenesis in PTEN-deficient mice. Biochem. J. 412, 211-221.

Hwang, J. T., Kim, Y. M., Surh, Y. J., Baik, H. W., Lee, S. K., Ha, J. and Park, O. J. (2006). Selenium regulates cyclooxygenase-2 and extracellular signal-regulated kinase signaling pathways by activating AMP-activated protein kinase in colon cancer cells. Cancer Res. 66, 10057-10063.

Inoki, K., Ouyang, H., Zhu, T., Lindvall, C., Wang, Y., Zhang, X., Yang, Q., Bennett, C., Harada, Y., Stankunas, K. et al. (2006). TSC2 integrates Wnt and energy signals via a coordinated phosphorylation by AMPK and GSK3 to regulate cell growth. Cell 126, 955-968.

Jäger, S., Handschin, C., St-Pierre, J. and Spiegelman, B. M. (2007). AMP-activated protein kinase (AMPK) action in skeletal muscle via direct phosphorylation of PGC1alpha. Proc. Natl. Acad. Sci. USA 104, 12017-12022.

Ji, C., Yang, B., Yang, Y. L., He, S. H., Miao, D. S., He, L. and Bi, Z. G. (2010). Exogenous cell-permeable C6 ceramide sensitizes multiple cancer cell lines to Doxorubicin-induced apoptosis by promoting AMPK activation and mTORC1 inhibition. Oncogene 29, 6557-6568.

Kahn, B. B., Alquier, T., Carling, D. and Hardie, D. G. (2005). AMP-activated protein kinase: ancient energy gauge provides clues to modern understanding of metabolism. Cell Metab. 1, 15-25.

Kawaguchi, T., Osatomi, K., Yamashita, H., Kabashima, T. and Uyeda, K. (2002). Mechanism for fatty acid "sparing" effect on glucose-induced transcription: regulation of carbohydrate-responsive element-binding protein by AMP-activated protein kinase. J. Biol. Chem. 277, 3829-3835.

Kilbride, S. M., Farrelly, A. M., Bonner, C., Ward, M. W., Nyhan, K. C., Concannon, C. G., Wollheim, C. B., Byrne, M. M. and Prehn, J. H. (2010). AMPactivated protein kinase mediates apoptosis in response to bioenergetic stress through activation of the pro-apoptotic Bcl-2 homology domain-3-only protein BMF. J. Biol. Chem. 285, 36199-36206.

Kim, J., Kundu, M., Viollet, B. and Guan, K. L. (2011). AMPK and mTOR regulate autophagy through direct phosphorylation of Ulk1. Nat. Cell Biol. 13, 132-141.

Kroemer, G. and Pouyssegur, J. (2008). Tumor cell metabolism: cancer's Achilles' heel. Cancer Cell 13, 472-482.

Kroemer, G., Mariño, G. and Levine, B. (2010). Autophagy and the integrated stress response. Mol. Cell 40, 280-293

Kurth-Kraczek, E. J., Hirshman, M. F., Goodyear, L. J. and Winder, W. W. (1999). 5 ' AMP-activated protein kinase activation causes GLUT4 translocation in skeletal muscle. Diabetes 48, 1667-1671. 
Lee, Y. K., Hwang, J. T., Kwon, D. Y., Surh, Y. J. and Park, O. J. (2010). Induction of apoptosis by quercetin is mediated through AMPKalpha1/ASK1/p38 pathway. Cancer Lett. 292, 228-236.

Levine, Y. C., Li, G. K. and Michel, T. (2007). Agonist-modulated regulation of AMPactivated protein kinase (AMPK) in endothelial cells. Evidence for an AMPK $\rightarrow$ Rac $\rightarrow$ Akt $\rightarrow$ endothelial nitric-oxide synthase pathway. J. Biol. Chem. 282, 2035120364.

Li, J., Miller, E. J., Ninomiya-Tsuji, J., Russell, R. R., 3rd and Young, L. H. (2005) AMP-activated protein kinase activates p38 mitogen-activated protein kinase by increasing recruitment of p38 MAPK to TAB1 in the ischemic heart. Circ. Res. 97, 872-879.

Li, J., Zeng, Z., Viollet, B., Ronnett, G. V. and McCullough, L. D. (2007) Neuroprotective effects of adenosine monophosphate-activated protein kinase inhibition and gene deletion in stroke. Stroke 38, 2992-2999.

Liu, L., Hausladen, A., Zeng, M., Que, L., Heitman, J. and Stamler, J. S. (2001). A metabolic enzyme for S-nitrosothiol conserved from bacteria to humans. Nature $\mathbf{4 1 0}$ 490-494.

Long, Y. C. and Zierath, J. R. (2006). AMP-activated protein kinase signaling in metabolic regulation. J. Clin. Invest. 116, 1776-1783.

Mariño, G., Madeo, F. and Kroemer, G. (2011). Autophagy for tissue homeostasis and neuroprotection. Curr. Opin. Cell Biol. 23, 198-206.

McBride, A., Ghilagaber, S., Nikolaev, A. and Hardie, D. G. (2009). The glycogenbinding domain on the AMPK beta subunit allows the kinase to act as a glycogen sensor. Cell Metab. 9, 23-34

McCullough, L. D., Zeng, Z., Li, H., Landree, L. E., McFadden, J. and Ronnett, G. V. (2005). Pharmacological inhibition of AMP-activated protein kinase provides neuroprotection in stroke. J. Biol. Chem. 280, 20493-20502.

Memmott, R. M., Gills, J. J., Hollingshead, M., Powers, M. C., Chen, Z., Kemp, B. Kozikowski, A. and Dennis, P. A. (2008). Phosphatidylinositol ether lipid analogues induce AMP-activated protein kinase-dependent death in LKB1-mutant non small cell lung cancer cells. Cancer Res. 68, 580-588.

Merrill, G. F., Kurth, E. J., Hardie, D. G. and Winder, W. W. (1997). AICA riboside increases AMP-activated protein kinase, fatty acid oxidation, and glucose uptake in rat muscle. Am. J. Physiol. 273, E1107-E1112.

Mihaylova, M. M. and Shaw, R. J. (2011). The AMPK signalling pathway coordinates cell growth, autophagy and metabolism. Nat. Cell Biol. 13, 1016-1023.

Mitchelhill, K. I., Michell, B. J., House, C. M., Stapleton, D., Dyck, J., Gamble, J., Ullrich, C., Witters, L. A. and Kemp, B. E. (1997). Posttranslational modifications of the 5'-AMP-activated protein kinase betal subunit. J. Biol. Chem. 272, 2447524479.

Monami, M., Colombi, C., Balzi, D., Dicembrini, I., Giannini, S., Melani, C., Vitale, V., Romano, D., Barchielli, A., Marchionni, N. et al. (2011). Metformin and cancer occurrence in insulin-treated type 2 diabetic patients. Diabetes Care 34, 129-131.

Moncada, S. and Bolaños, J. P. (2006). Nitric oxide, cell bioenergetics and neurodegeneration. J. Neurochem. 97, 1676-1689.

Oakhill, J. S., Steel, R., Chen, Z. P., Scott, J. W., Ling, N., Tam, S. and Kemp, B. E. (2011). AMPK is a direct adenylate charge-regulated protein kinase. Science 332, 1433-1435.

Okoshi, R., Ozaki, T., Yamamoto, H., Ando, K., Koida, N., Ono, S., Koda, T., Kamijo, T., Nakagawara, A. and Kizaki, H. (2008). Activation of AMP-activated protein kinase induces p53-dependent apoptotic cell death in response to energetic stress. J. Biol. Chem. 283, 3979-3987.

Pan, W., Yang, H., Cao, C., Song, X., Wallin, B., Kivlin, R., Lu, S., Hu, G., Di, W. and Wan, Y. (2008). AMPK mediates curcumin-induced cell death in CaOV3 ovarian cancer cells. Oncol. Rep. 20, 1553-1559.

Piantadosi, C. A. (2011). Regulation of mitochondrial processes by protein Snitrosylation. Biochim. Biophys. Acta. (in press)

Poels, J., Spasić, M. R., Callaerts, P. and Norga, K. K. (2009). Expanding roles for AMP-activated protein kinase in neuronal survival and autophagy. Bioessays 31, 944 952.

Polekhina, G., Gupta, A., Michell, B. J., van Denderen, B., Murthy, S., Feil, S. C., Jennings, I. G., Campbell, D. J., Witters, L. A., Parker, M. W. et al. (2003). AMPK beta subunit targets metabolic stress sensing to glycogen. Curr. Biol. 13, 867 871.

Reihill, J. A., Ewart, M. A., Hardie, D. G. and Salt, I. P. (2007). AMP-activated protein kinase mediates VEGF-stimulated endothelial NO production. Biochem Biophys. Res. Commun. 354, 1084-1088.

Ronnett, G. V., Ramamurthy, S., Kleman, A. M., Landree, L. E. and Aja, S. (2009) AMPK in the brain: its roles in energy balance and neuroprotection. J. Neurochem. 109 Suppl. 1, 17-23.

Rosenfeldt, M. T. and Ryan, K. M. (2011). The multiple roles of autophagy in cancer Carcinogenesis 32, 955-963.

Sarkar, S., Korolchuk, V. I., Renna, M., Imarisio, S., Fleming, A., Williams, A., Garcia-Arencibia, M., Rose, C., Luo, S., Underwood, B. R. et al. (2011). Complex inhibitory effects of nitric oxide on autophagy. Mol. Cell 43, 19-32.

Scherz-Shouval, R., Shvets, E., Fass, E., Shorer, H., Gil, L. and Elazar, Z. (2007) Reactive oxygen species are essential for autophagy and specifically regulate the activity of Atg4. EMBO J. 26, 1749-1760.

Scott, J. W., Hawley, S. A., Green, K. A., Anis, M., Stewart, G., Scullion, G. A., Norman, D. G. and Hardie, D. G. (2004). CBS domains form energy-sensing modules whose binding of adenosine ligands is disrupted by disease mutations. $J$. Clin. Invest. 113, 274-284.
Spencer, B., Potkar, R., Trejo, M., Rockenstein, E., Patrick, C., Gindi, R., Adame, A. Wyss-Coray, T. and Masliah, E. (2009). Beclin 1 gene transfer activates autophagy and ameliorates the neurodegenerative pathology in alpha-synuclein models of Parkinson's and Lewy body diseases. J. Neurosci. 29, 13578-13588.

Steinberg, G. R. and Kemp, B. E. (2009). AMPK in health and disease. Physiol. Rev. 89, 1025-1078.

Tennant, D. A., Durán, R. V. and Gottlieb, E. (2010). Targeting metabolic transformation for cancer therapy. Nat. Rev. Cancer 10, 267-277.

Trachootham, D., Alexandre, J. and Huang, P. (2009). Targeting cancer cells by ROS-mediated mechanisms: a radical therapeutic approach? Nat. Rev. Drug Discov. 8, 579-591.

Tzatsos, A. and Tsichlis, P. N. (2007). Energy depletion inhibits phosphatidylinositol 3 kinase/Akt signaling and induces apoptosis via AMP-activated protein kinasedependent phosphorylation of IRS-1 at Ser-794. J. Biol. Chem. 282, 18069-18082.

Underwood, B. R., Imarisio, S., Fleming, A., Rose, C., Krishna, G., Heard, P., Quick, M., Korolchuk, V. I., Renna, M., Sarkar, S. et al. (2010). Antioxidants can inhibit basal autophagy and enhance neurodegeneration in models of polyglutamine disease. Hum. Mol. Genet. 19, 3413-3429.

Vingtdeux, V., Chandakkar, P., Zhao, H., d'Abramo, C., Davies, P. and Marambaud, P. (2011). Novel synthetic small-molecule activators of AMPK as enhancers of autophagy and amyloid- $\beta$ peptide degradation. FASEB J. 25, 219-231.

Vingtdeux, V., Giliberto, L., Zhao, H., Chandakkar, P., Wu, Q., Simon, J. E., Janle, E. M., Lobo, J., Ferruzzi, M. G., Davies, P. et al. (2010). AMP-activated protein kinase signaling activation by resveratrol modulates amyloid-beta peptide metabolism. J. Biol. Chem. 285, 9100-9113.

Viollet, B., Mounier, R., Leclerc, J., Yazigi, A., Foretz, M. and Andreelli, F. (2007). Targeting AMP-activated protein kinase as a novel therapeutic approach for the treatment of metabolic disorders. Diabetes Metab. 33, 395-402.

Weisová, P., Dávila, D., Tuffy, L. P., Ward, M. W., Concannon, C. G. and Prehn, J. H. (2011). Role of $5^{\prime}$-adenosine monophosphate-activated protein kinase in cell survival and death responses in neurons. Antioxid. Redox Signal. 14, 1863-1876.

Winder, W. W. and Hardie, D. G. (1996). Inactivation of acetyl-CoA carboxylase and activation of AMP-activated protein kinase in muscle during exercise. Am. J. Physiol. 270, E299-E304

Winder, W. W. and Hardie, D. G. (1999). AMP-activated protein kinase, a metabolic master switch: possible roles in type 2 diabetes. Am. J. Physiol. 277, E1-E10.

Wong, E. and Cuervo, A. M. (2010). Autophagy gone awry in neurodegenerative diseases. Nat. Neurosci. 13, 805-811.

Xiao, B., Heath, R., Saiu, P., Leiper, F. C., Leone, P., Jing, C., Walker, P. A., Haire, L., Eccleston, J. F., Davis, C. T. et al. (2007). Structural basis for AMP binding to mammalian AMP-activated protein kinase. Nature 449, 496-500.

Xiao, B., Sanders, M. J., Underwood, E., Heath, R., Mayer, F. V., Carmena, D., Jing, C., Walker, P. A., Eccleston, J. F., Haire, L. F. et al. (2011). Structure of mammalian AMPK and its regulation by ADP. Nature 472, 230-233.

Xie, Z., Dong, Y., Zhang, M., Cui, M. Z., Cohen, R. A., Riek, U., Neumann, D., Schlattner, U. and Zou, M. H. (2006). Activation of protein kinase C zeta by peroxynitrite regulates LKB1-dependent AMP-activated protein kinase in cultured endothelial cells. J. Biol. Chem. 281, 6366-6375.

Yang, P. M., Liu, Y. L., Lin, Y. C., Shun, C. T., Wu, M. S. and Chen, C. C. (2010). Inhibition of autophagy enhances anticancer effects of atorvastatin in digestive malignancies. Cancer Res. 70, 7699-7709.

Yu, L. F., Qiu, B. Y., Nan, F. J. and Li, J. (2010). AMPK activators as novel therapeutics for type 2 diabetes. Curr. Top. Med. Chem. 10, 397-410.

Zhang, J., Xie, Z., Dong, Y., Wang, S., Liu, C. and Zou, M. H. (2008). Identification of nitric oxide as an endogenous activator of the AMP-activated protein kinase in vascular endothelial cells. J. Biol. Chem. 283, 27452-27461.

Zhang, W. B., Wang, Z., Shu, F., Jin, Y. H., Liu, H. Y., Wang, Q. J. and Yang, Y. (2010). Activation of AMP-activated protein kinase by temozolomide contributes to apoptosis in glioblastoma cells via p53 activation and mTORC1 inhibition. J. Biol. Chem. 285, 40461-40471.

Zheng, D., MacLean, P. S., Pohnert, S. C., Knight, J. B., Olson, A. L., Winder, W. W. and Dohm, G. L. (2001). Regulation of muscle GLUT-4 transcription by AMP-activated protein kinase. J. Appl. Physiol. 91, 1073-1083.

Zhou, G., Myers, R., Li, Y., Chen, Y., Shen, X., Fenyk-Melody, J., Wu, M., Ventre, J., Doebber, T., Fujii, N. et al. (2001). Role of AMP-activated protein kinase in mechanism of metformin action. J. Clin. Invest. 108, 1167-1174.

Zhou, G., Sebhat, I. K. and Zhang, B. B. (2009). AMPK activators--potential therapeutics for metabolic and other diseases. Acta Physiol. (Oxf.) 196, 175-190.

Zmijewski, J. W., Banerjee, S., Bae, H., Friggeri, A., Lazarowski, E. R. and Abraham, E. (2010). Exposure to hydrogen peroxide induces oxidation and activation of AMP-activated protein kinase. J. Biol. Chem. 285, 33154-33164.

Zong, H., Ren, J. M., Young, L. H., Pypaert, M., Mu, J., Birnbaum, M. J. and Shulman, G. I. (2002). AMP kinase is required for mitochondrial biogenesis in skeletal muscle in response to chronic energy deprivation. Proc. Natl. Acad. Sci. USA 99, 15983-15987.

Zou, M. H., Kirkpatrick, S. S., Davis, B. J., Nelson, J. S., Wiles, W. G. 4th, Schlattner, U., Neumann, D., Brownlee, M., Freeman, M. B. and Goldman, M. H. (2004). Activation of the AMP-activated protein kinase by the anti-diabetic drug metformin in vivo. Role of mitochondrial reactive nitrogen species. J. Biol. Chem. 279, 43940-43951 